\title{
Dorottya Fabian, A Musicology of Performance: Theory and Method Based on Bach's Solos for Violin
}

(Cambridge, UK: Open Book Publishers, 2015)

ISBN Hardback: 978-1-78374-153-3

The somewhat surprising title of Dorottya Fabian's book signifies a new quality in the approach of its subject matter in the most concise manner. Interpretation and performance have been in the forefront of recent publications on music, gradually broadening the scope of pragmatic and non-pragmatic investigations, but Fabian's title is almost a proclamation of a new discipline. To regard the study of performance - traditionally considered a hazardous undertaking from the scholarly point of view - as part of hard-core musicology is a brave proposition indeed.

Not that the way has not been prepared by Dorottya Fabian's numerous earlier publications. Her Bach Performance Practice, 1945-1975: A Comprehensive Review of Sound Recordings and Literature (Ashgate, 2003) examined all the commercially available recordings of the Passions, Brandenburg Concertos, and Goldberg Variations; the essay "Towards a Performance History of Bach's Sonatas and Partitas for Solo Violin" (in Essays in Honor of László Somfai, Scarecrow, 2005) is a small-scale prelude to the present book. Parallel with the exhaustive Bach analyses, Fabian became a prominent leader in the "movement" of treating performance issues through experimental research. She and her co-workers (at times co-authors) have published extensively on several aspects of musical performance (often in online editions) with remarkable results. Their latest major achievement, a volume produced through joint editorial undertaking, offers a comprehensive 
account of the means, roles, and manifestations of expressiveness in the performance of Classical music as well as in jazz, popular music, and folk music. ${ }^{1}$

A Musicology of Performance offers an admirably wide spectrum of approximately 40 different recordings of J. S. Bach's Six Sonatas and Partitas for Solo Violin (BWV 1001-1006) made during the past thirty years or so. (Thus, in a chronological sense, the volume is a continuation of Fabian's former Bach Performance Practice book, now focusing on another genre.) As far as the selected violinists are concerned, they represent historically informed as well as mainstream performance styles, from Ruggiero Ricci and Itzhak Perlman to Julia Fischer and Isabelle Faust, or Jaap Schröder and Sigiswald Kuijken to Rachel Podger. (The pioneer recording of Sergiu Luca, from 1977, is naturally noted as an early herald of the subsequent interpretations on period instrument.)

Fabian classifies the violinists as followers of historically informed performance (HIP), or mainstream performance (MSP). She maintains this distinction through the entire course of her discussions, notwithstanding that a clear line of demarcation is less and less feasible as we proceed into the twenty-first century. (And a very healthy phenomenon that is.) As a point of departure, the author defines the constituents of performance (phrasing; articulation and accentuation; bowing; multiple stops; ornamentation; rubato; rhythm; vibrato; dynamics), describes their realization in HIP and MSP manner respectively, then lists the selected violinists' interpretative styles accordingly, in the six solo works of Bach, movement by movement.

The methods used for the minute measurement of the above parameters are based on computer technology, through various software programs. Absolutely scientific data are produced, presented in elaborate tables, figures, and graphs. Looking at some of them, the innocent reader would not guess that the book he/ she holds was written about music. The text, too, sounds pretty heavy at times. (See note 4 on p. 132, for instance, illuminating a summary of tempo trends in Table 4.1: "R-squared is a statistical measure of how close the data points are to the fitted regression line. It is a measure of variance explained.")

Nevertheless, cognitive/computational musicology gains more and more ground nowadays, perhaps to prove that this branch of knowledge can hold its own when compared to the field of natural sciences. To my amazement, the content of the 43/4 (Nov 2015) issue of the journal Early Music, under the general title "Early music and modern technology," assumes the aspect of a computer journal. Transforming Musicology ("Exploring information retrieval, semantic technologies and workflows for music scholarship: the Transforming Musicology project"); A Big Data History of Music; Lexomics ("Text mining and early music: using Lexomics

1. Dorottya Fabian, Renee Timmers, Emery Schubert (eds), Expressiveness in Music Performance: Empirical Approaches across Styles and Cultures (Oxford University Press, 2014). 
in research") are some of the subjects. The illustrative material consists of dendrograms, charts, network diagrams, and the like. The use of online databases and resources in our field is indisputable, of course; but I, for one, am a bit sceptical about the musical effectiveness of the Lassus research carried by the ELVIS ("Electronic Locator of Vertical Interval Successions") project of McGill University.

Computer technology is the basic tool of the investigations in Dorottya Fabian's book, too. As a general introduction, however, Theoretical Matters are expounded before the detailed discussion of Bach's Solos. The author opens this section as follows:

Music performance is a rich, multi-dimensional phenomenon that has fascinated philosophers, historians, analysts, psychologists, cognitive and neuro-scientists as well as anthropologists and cultural theorists. People have studied it from various angles and disciplines arriving at important partial insights. In this chapter I review (necessarily very selectively) some of the key developments in this broad field leading to my proposition that music performance is too complex to be understood by any one approach. We need multi-modal and transdisciplinary, comprehensive accounts that are data-driven yet embrace the phenomenological and cultural if we wish to lessen the problem of verbalizing an embodied aural experience. (p. 25)

Under the headings of Theoretical Matters, interesting subtitles appear: "Modernism versus Postmodernism"; "HIP as a Mirror of Cultural Change"; "Empirical and Psychological Studies in Performance"; etc. Among them, we find an excursus into philosophy, through the ideas of the French writer and "antirationalist philosopher" (Encyclopaedia Britannica), Gilles Deleuze ("Music Performance and Complex Systems").

It has been chic in recent musicological discourses to turn to literary criticism and philosophy, for highbrow discussion of musical matters. The names of Gadamer, Derrida, Foucault, Saussure, and others appear frequently on the pages of any serious book on music today, often to prove the superior intention or the well-informed position of the author. Fabian's candidate is Gilles Deleuze, whose philosophical theses serve a background for the dissection of performance questions. Based mainly on A Thousand Plateaus by Gilles Deleuze and Felix Guattari, the subchapters "G. Deleuze and Difference in Music Performance," and "Music Performance as Complex Dynamical System" apply Deleuze's philosophy of difference to musical interpretation. The parallel is expressed so strongly, that the terminology of Deleuze's language is used throughout the book (territorialization; deterritorialization; assemblage; rhizome; molar and molecular lines; etc.). I do not feel qualified to judge whether these parallels help to understand the mysteries of musical performance or not. Perhaps they do. 
When coming to grips with the true musical and stylistic components of the interpretation, the analytical methods of the book are fascinating, and the results are manifold. Perhaps the most important conclusion concerns a new kind of diversity in musical performance. In recent literature numerous jeremiads commented on the uniformity ("Urtext mentality") of the musical interpretations of the post-war period in general and early recordings of c. 1900 have been praised and advertised as true models of an art characterized by personality, freedom, and imagination. Dorottya Fabian asserts that during the past few decades the much lamented literal approach has gradually faded out and a new performance style is gaining ground, one which offers a large scope again to variety and personal expression.

As the detailed examinations, and great number of examples of the book prove, this new quality is mainly due to the interaction between HIP and MSP tendencies, resulting in a healthy pluralism in performance manners. (Although the investigations were carried out in a particular genre by a particular composer, the consequences probably possess a wider validity.) It is remarkable indeed how the best aspects of historically informed performance has influenced and inspired the best players, whether using period instruments or not. The liberating effect of the more spontaneous, at times improvisatory approach to Bach's music has brought wonderful results in the past decades - one has perceived that, even without scholarly reports such as the present volume. Ornamentation, it seems, had a particular attraction to MSP violinists, as Fabian describes in the course of "Analyses of Performance Features":

In my earlier work on Bach performance practice in the twentieth century I argued that ornamentation, together with the use of period instruments, was a less important matter in establishing the style of a performance than rhythmic projection and articulation. I came to this conclusion in relation to performance from the 1950 s to the 1970 s and to that extent I still stand by my opinion. However, in the examination of the current body of recordings, ornamentation turned out to be one of the most rewarding aspects of study. Not just in providing thrill and pleasure while listening but also because it emerged as an important indicator of how far the HIP movement has developed. In effect I am now inclined to claim that ornamentation is perhaps the most obvious signifier of advanced HIP style. (p. 120)

Therefore, the important sequel of Dorottya Fabian's systematic work is a truly stirring one: among the latest recordings of Bach's solo violin compositions the most stimulating and novel performances are offered by those artists who play on modern violins and basically represent "mainstream" tradition, but have been profoundly influenced by the principles of the historical approach. In this respect, in the panorama of Fabian's violinists, perhaps Victoria Mullova stands out as the strongest, most imposing musical personality. 
Next to the general discussions of performance features, the author draws living and sounding portraits of dozens of violinists. Her sound musical judgement lends authority to her observations: indeed, that is the foundation of all her statements, valuations, and conclusions. And that distinguishes her thoughts from those of some colleagues, who, in similar investigations, note parenthetically that beyond the methods of cognitive and computational musicology, "more sight is needed regarding possible effects of aesthetics on instrumental practice."

The amount and variety of the illustrative material of the volume is staggering. In addition to the spectrograms, graphs, and other computer-based figures there are tables, musical examples, and - most importantly - dozens of audio examples. Short excerpts from the Bach movements are selected to compare the interpretations of different players, or different recordings of the same artist. In each case precise data of the particular link is given to help the reader to easy accessibility. This aural experience - needless to say - is the greatest bonus in the appreciation of the tremendous variety offered by the approximately forty different recordings.

"As with all Open Book publications, the entire work is available free to read online, while printable digital editions of the volume together with additional resources can be downloaded from the publisher's website," reads the information on the back cover of the book. A generous premium indeed, especially for students who could hardly afford to buy expensive academic research literature. On the whole, Open Book Publishers did a good job with the production of the text, although errors and deficiencies do occur. The most unfortunate lapsus appears in the Figure 4.4a musical example (p. 159), where the full six beginning bars of the B-minor Sarabande are notated a second higher than their proper key. Misprints slipped into Table 4.1 (p. 132); "Figures 5.5 and 5.6" should be correctly identified as "Figures 5.2 and 5.3" in the bottom line of p. 214. The general British use of note values is changed illogically into American usage in Table 4.8 (p. 187). Quite defective - in fact, entirely random - is the Index at the close of the volume. Key figures of the chapters (David Oistrakh, Henryk Szeryng, Yehudi Menuhin, Isaac Stern, Anne-Sophie Mutter, Dénes Zsigmondy, Stanley Ritchie, Malcolm Bilson, and many others) are simply left out from the list of names and terms.

"Data can't solve aesthetic issues," declared star musicologist Richard Taruskin in a keynote address in $2011 .{ }^{3}$ I do not know that I do not agree with him, after all. Musical performance is an utterly personal matter and to take it to pieces in an intrusive manner seems almost indiscreet. Furthermore, here is the capital question of live performance versus recording. In spite of recent professional opinion, I still maintain that an artificially fixed performance can never have the

2. Carlos Vaquero, "A quantitative study of seven historically informed performances of Bach's BWV 1007 prelude," Early Music 43/4 (November 2015), 611-622. The author is a PhD candidate at the Institute for Logic, Language and Computation of the University of Amsterdam.

3. "How Things Stand Now?" keynote address delivered at the Performa '11 Conference, Aveiro, Portugal, 19 May 2011. 
hic et nunc spontaneity of a live production. According to Nikolaus Harnoncourt, the greatest moments of a performance are those where the greatest risk is taken by the performer. Now such moments are usually points of high emotion, where expressiveness takes a wonderfully unexpected turn, and the extreme nervous tension produces a strong psychological effect in the listener. Such effects can hardly be achieved by recordings.

There exists another side of the coin, however. General tendencies in the history of musical interpretation can surely be discerned and these periods or cycles should be examined by professional experts. This area of musicology - "a musicology of performance," if you like - has developed to a remarkable degree in recent decades, through interdisciplinary methods and procedures. Dorottya Fabian's new book is a significant station on the road.

Katalin Komlós 